\title{
A Competitive Polymerase Chain Reaction-Based Approach for the Identification and Semiquantification of Mitochondrial DNA in Differently Heat-Treated Bovine Meat and Bone Meal
}

\author{
DOMENICO FREZZA, ${ }^{1 *}$ MARCO FAVARO, ${ }^{1}$ GABRIELE VACCARI, ${ }^{2}$ CHRISTOPH vON-HOLST, ${ }^{3}$ \\ VINCENZO GIAMBRA, ${ }^{1}$ ELKE ANKLAM, ${ }^{3}$ DANIELA BOVE, ${ }^{4}$ PIERO A. BATTAGLIA, ${ }^{5}$ UMBERTO AGRIMI, ${ }^{2}$ \\ GIANFRANCO BRAMBILLA, ${ }^{2}$ PAOLO AJMONE-MARSAN, ${ }^{6}$ AND MARCO TARTAGLIA ${ }^{7} \dagger$
}

\begin{abstract}
${ }^{1}$ Dipartimento di Biologia, Universita' degli studi di Roma Tor-Vergata, Viale della Ricerca Scientifica, 00133 Rome, Italy; ${ }^{2}$ Laboratorio di Medicina Veterinaria, ${ }^{5}$ Biologia Cellulare, ${ }^{7}$ Metabolismo e Biochimica Patologica, Istituto Superiore di Sanita', Rome, Italy; ${ }^{3}$ European Commission, DG Joint Research Centre, Institute for Reference Materials and Measurements, Food \& Feed Unit, Ispra, Varese, Italy; ${ }^{4}$ Istituto Zooprofilattico Sperimentale del Mezzogiorno, Portici, Naples, Italy; and ${ }^{6}$ Laboratorio di Genetica, Istituto di Zootecnia dell' Universita' Cattolica del Sacro Cuore, Piacenza, Italy
\end{abstract}

MS 02-46: Received 5 March 2002/Accepted 19 July 2002

\begin{abstract}
The risk of bovine spongiform encephalopathy propagation was drastically reduced after the European Union (EU) Health Authorities adopted restrictions involving a ban on animal-derived proteins in the diet of farm animals. Currently, the EU's officially recommended method for controlling meat and bone meal (MBM) in animal feed is the microscopic method, which involves the identification of bone fragments on the basis of their morphological characteristics. Recently, we demonstrated that a polymerase chain reaction (PCR)-based assay can be used for the detection of taxon-specific DNA in MBM and animal feeds. To ensure the safe rendering of animal by-products, the EU Council requires that this material be treated at $133^{\circ} \mathrm{C}$ at $300 \mathrm{kPa}$ for $20 \mathrm{~min}$. Here we investigate the relationship between DNA degradation, PCR amplification, and MBM heat treatment. With a competitive PCR-based approach, we compare the amplification efficiency of bovine mitochondrial DNA target sequences of different lengths in several heat-treated MBM samples. For our method, a synthetic competitive DNA is used as an internal control for both DNA extraction and PCR reaction. A correlation between an increase in treatment temperature and a reduction in the size of the target sequences suitable for amplification was observed, suggesting progressive DNA fragmentation due to the temperature. We show that short amplicons (147 bp) can be used to detect the presence of bovine mtDNA in MBM samples treated according to the current European regulations. The use of such a competitive approach to compare amplification efficiency levels of targets of different lengths might represent a useful tool for the determination of both the amount of MBM in animal feeds and its proper heat treatment.
\end{abstract}

There is evidence that bovine spongiform encephalopathy (BSE) was spread around the world through animal feed containing infected meat and bone meal (MBM) (3, 4). The effective preventive measures taken by the United Kingdom with the introduction of the so-called "real feed ban" in 1996 (a ban on animal proteins in farm animal feeds) have led to a rapid reduction in the appearance of new cases in that country (5). Based on such epidemiological evidence, national and international authorities (Office International des Epizooties, the World Health Organization, Codex Alimentarius, and the European Commission) have progressively implemented specific legislation and guidelines regarding the appropriate heat treatment of MBMs (10), the ban of MBMs from ruminant feeds (6), and the removal of specified risk materials from slaughtered ruminants (8). Currently, there is a temporary ban on animal meal in feed for all animals intended for human consumption within the European Union (EU), allowing mem-

\footnotetext{
* Author for correspondence. Tel: 39 (06) 72594814; Fax: 39 (06) 2023500; E-mail: frezza@uniroma2.it.

$\dagger$ Present address: Department of Human Genetics, Mount Sinai School of Medicine, One Gustave Levy Place, Box 1498, New York, NY 10029, USA.
}

ber states to improve the practical implementation of the European legislation to prevent the spread of BSE (9).

Nevertheless, there is currently no reliable, sensitive, and specific method to detect the presence of the BSE causative agent in feeds. Therefore, only indirect approaches testing for the presence of animal constituents in ruminant feeds have been proposed and applied $(1,16,17,19-22$, 28). Currently, the method officially recommended by the EU for the control of MBM in animal feeds is the microscopic method, which involves the identification of an animal species through analysis of the tissue constituents (mainly bone fragments) on the basis of their morphological characteristics (7).

Recently, we demonstrated that a polymerase chain reaction (PCR)-based assay allows the detection of taxonspecific DNA in MBM and animal feeds (28). In the present study we investigated the relationship between DNA degradation and MBM heat treatment. We compared the amplification efficiency levels of bovine mitochondrial DNA (mtDNA) sequences of different lengths by using DNA extracts obtained from differentially heat treated MBM samples. A competitive PCR-based approach was applied for a semiquantitative evaluation of target mtDNA $(12,24,31)$. 
Such an approach consists of the coextraction of a known amount of an appropriately selected synthetic template together with the total DNA present in the MBM, followed by its coamplification together with the target sequence of interest using a single primer pair. Because of primer annealing competition and homologous amplification kinetics, the ratio between the synthetic and the target molecules remains constant during the reaction, and the final abundance of both synthetic and target products is dependent solely on the initial ratio between target and competitive molecules. Titration with a dilution series of the competitive template allows the determination of the equivalent point at which the competitive DNA and the target template concentrations are equal, consequently revealing the relative quantity of target DNA in a given amount of MBM $(26,30)$.

The purpose of the present study was to highlight the correlation between heat treatment and a reduction in the size of the template suitable for amplification, which indicates a progressive DNA fragmentation due to increasing temperatures. The final aim of the present work was to determine whether PCRs designed through the adoption of short amplicons as target sequences could allow the detection of bovine mtDNA in MBM samples treated according to the European regulations $\left(133^{\circ} \mathrm{C}, 300 \mathrm{kPa}, 20 \mathrm{~min}\right)$ and whether such a competitive PCR approach is a useful tool with which to determine the proper heat treatment of MBM and to estimate its amount in feeds.

\section{MATERIALS AND METHODS}

Test materials. Five differently prepared MBM samples (MBM-I through MBM-V) were used in the present study. With the exception of MBM-IV, which was prepared with $100 \%$ bovine material, all of the MBM samples used in this study comprised a mixture of $50 \%$ of swine and $50 \%$ bovine materials. A batch type system was used to produce MBM-I and MBM-II in the same commercial rendering plant $(14,15)$. The production plant equipment included two cylinder-shaped sterilizers equipped with a stirrer. For the sterilization process, the stirrer and the longitudinal walls were heated with steam. Temperature and pressure sensors were installed on the walls of the large-scale autoclave that were not heated, thus ensuring that the temperature was measured at the coolest point in the vessel. The process comprised the following steps. The particle sizes of the animal by-products were reduced with a prebreaker, and this material was sterilized in the autoclave under wet conditions. Subsequently, the processed material was dried in a disk dryer and the hot material was pressed to remove the fat. Finally, the material was ground in a hammer mill. MBM-I was processed in compliance with European legislation (10). According to the technical annex of this legislation, the sterilization temperature, pressure, and time must be at least $133^{\circ} \mathrm{C}, 300 \mathrm{kPa}$, and $20 \mathrm{~min}$, respectively. In addition, the maximum particle size of the processed animal by-products was set at $50 \mathrm{~mm}$, and the pressure was produced by saturated steam to ensure that the sterilization took place in wet conditions.

MBM-II was prepared under the same conditions as MBMI except for the temperature and pressure, which were decreased to $130 \pm 1{ }^{\circ} \mathrm{C}$ and $270 \mathrm{kPa}$, respectively. Therefore, MBM-II did not comply with the European standard. Both materials were processed from whole carcasses and included waste from slaughterhouses (2).
MBM-III and MBM-V, which were also produced in a commercial processing plant, included animal by-products made up of bones and meals, but carcasses were not used. Unlike MBM-I and MBM-II, MBM-III and MBM-V were heat treated under dry conditions without overpressure. The process consisted of the following steps. Initially, the crushed raw material was heated to $80 \pm$ $1{ }^{\circ} \mathrm{C}$ to remove the liquefied fat. Subsequently, the degreased wet material was dried in a disk dryer and ground. MBM-III was further treated for dry sterilization with the temperature increasing from 90 to $140^{\circ} \mathrm{C}$ for $105 \mathrm{~min}$ (the temperature was $>133^{\circ} \mathrm{C}$ for $20 \mathrm{~min}$ ) without overpressure. The process for MBM-III and MBM-V did not satisfy the European rendering standard because no overpressure was applied.

MBM-IV was prepared with $5 \mathrm{~kg}$ of boneless $100 \%$ bovine meat (maximum particle size $50 \mathrm{~mm}$ ) and treated at $200 \mathrm{kPa}$ at $122^{\circ} \mathrm{C}$ for $20 \mathrm{~min}$ in a 20 -liter experimental autoclave with an internal stirrer and electric heaters. Conditions were controlled by internal temperature and pressure sensors (with a precision of $\left.\pm 1^{\circ} \mathrm{C}\right)$. No water was added during the process.

DNA extraction and gel electrophoresis analysis. DNA was extracted according to BACC-3 Amersham (Uppsala, Sweden) protocols involving the addition of $0.5 \mathrm{ml}$ of lysing buffer to $50 \mathrm{mg}$ of MBM samples, and the suspension was mixed without vortexing in order to avoid further DNA damage. The total DNA extracted after precipitation was resuspended in $100 \mu 1$ Tris-EDTA buffer, and $5 \mu \mathrm{l}$ of this volume was used as a template for all of the PCR amplifications reported. For competitive PCR assays, DNA was extracted by the same procedure with $10 \mu \mathrm{l}$ of the appropriate dilution of competitive plasmid DNA being added to the suspension of lysing buffer and MBM.

For genomic DNA degradation analysis, 5 to $15 \mu$ l of DNA extracted from MBM samples was mixed with $3 \mu$ of gel loading buffer $(0.04 \%$ bromophenol blue, $0.04 \%$ xylene cyanol, and $5 \%$ glycerol) and loaded on $0.8 \%$ agarose gel containing ethidium bromide $(0.5 \mathrm{mg} / \mathrm{ml})$. Electrophoresis was performed at $85 \mathrm{~V}$ for $1 \mathrm{~h}$; fragments were visualized on a long-wavelength UV transilluminator. The electrophoresis analyses of PCR products were performed under the same conditions but with $3 \%$ gel agarose.

Bovine-specific mtDNA primer pairs and PCR settings. mtDNA was chosen as the target molecule because of its abundance in tissues compared with genomic DNA $(18,23)$. We considered the sequence encompassing the ATPase8 and ATPase6 genes (Fig. 1). This region was targeted because of its low level of intraspecies variability and its relatively high degree of variation among vertebrates, even among Artiodactyla $(25,27,28)$. The primers used were L8129 (forward; 5'-GCC ATA TAC TCT CCT TGG TGA CA-3'), L8159 (forward; 5'-CTA GAC ACG TCA ACA TGA CTG A-3'), L8249 (forward; 5'-CAC AAT CCA GAA CTG ACA C-3'), and H8357 (reverse; 5'-GTA GGC TTG GGA ATA GTA CGA-3'). The three forward primers were used together with the reverse primer to obtain three products of different lengths: 271 bp (L8129/H8357), 240 bp (L8159/H8357), and 147 bp (L8249/H8357). PCRs were carried out in 50- $\mu 1$ reaction volumes containing $5 \mu \mathrm{l}$ of extracted DNA, $1 \mathrm{U}$ of Pharmacia (Uppsala, Sweden) Taq polymerase, 12.5 pmol of each primer, $1.5 \mathrm{mM}$ $\mathrm{MgCl}_{2}, 50 \mu \mathrm{M}$ each dNTP, and $1 \times$ buffer (Pharmacia) with the GeneAmp PCR System 9700 (Applied Biosystems, Foster City, Calif.). The cycling parameters were as follows: $94^{\circ} \mathrm{C}$ for $2 \mathrm{~min}$ (first denaturing step); 35 cycles of $94^{\circ} \mathrm{C}$ for $1 \mathrm{~min}, 58^{\circ} \mathrm{C}$ for 30 $\mathrm{s}$, and $72^{\circ} \mathrm{C}$ for $30 \mathrm{~s}$; and $72^{\circ} \mathrm{C}$ for $5 \mathrm{~min}$ (final extension step). To prevent carryover contamination, pre-PCR and post-PCR procedures were carried out in separate rooms. PCR preparation procedures were carried out with dedicated equipment consisting of 


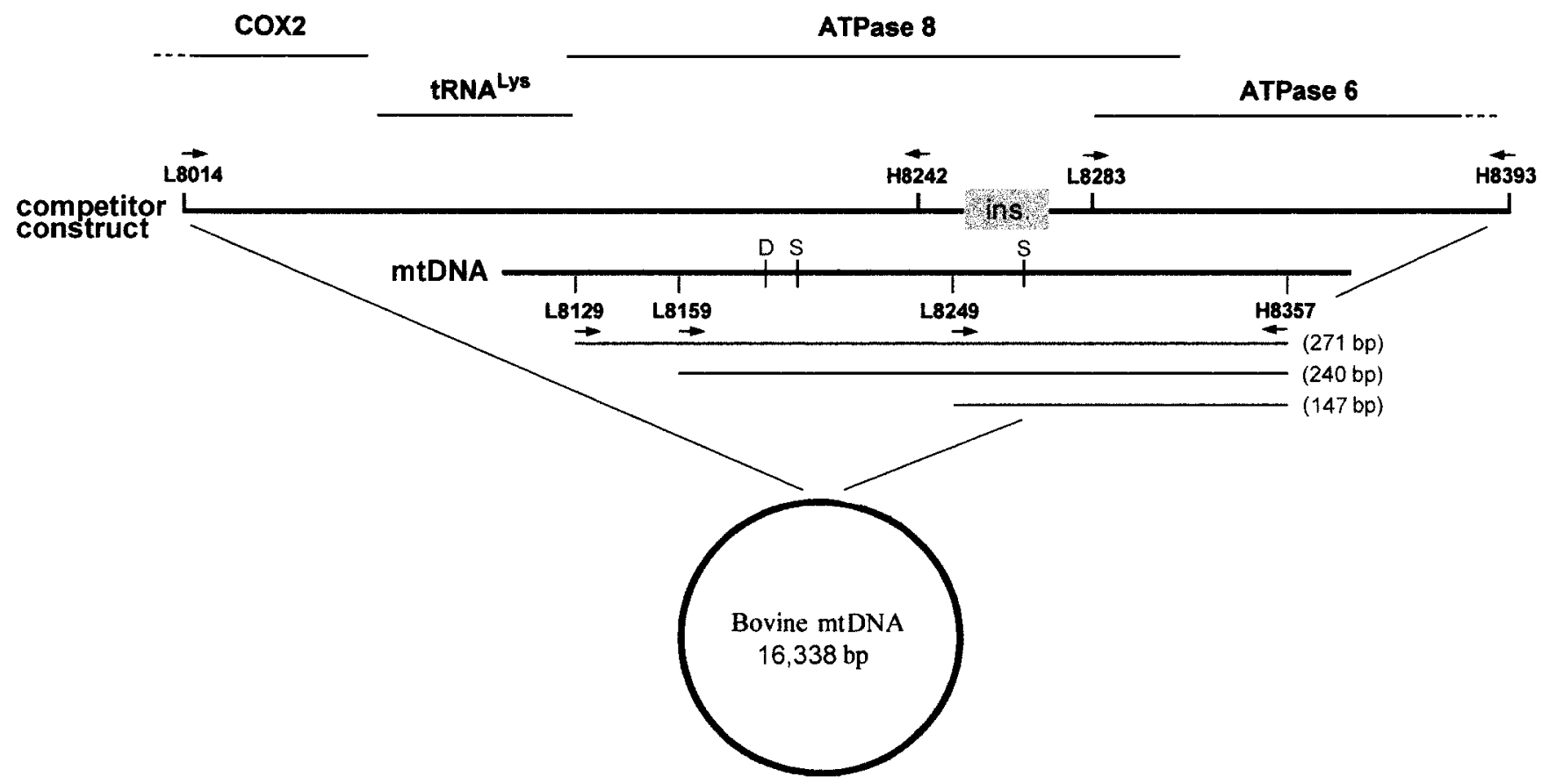

FIGURE 1. Structure of the bovine mtDNA competitor construct containing the 22-bp insertion (boxed). mtDNA includes the tRNA ${ }^{\text {Lys and }}$ ATPase 8 genes along with part of the COX2 gene and the ATPase6 gene. Primers L8014 (forward) and H8393 (reverse) amplify the 421-bp mtDNA fragment into which a 22-bp insertion was introduced by a three-step PCR procedure involving internal primers $H 8242$ (reverse) and L8283 (forward). Primers indicated in the mtDNA map below the construct amplify the three amplicons used in this study. Reverse primer $H 8357$ was coupled with forward primers L8129, L8159, and L8249 in order to amplify products of 271, 240 and 147 $b p$, respectively. The three amplicons are indicated by lines below the corresponding primers. Also shown on the map are the restriction sites for $\mathrm{DpnII}(D)$ and $\mathrm{SspI}(S)$ endonucleases, which discriminate the bovine-specific sequence from the ovine-and caprine-specific ones.

a laminar flow hood with aerosol-resistant plugged pipette tips (ART, Molecular Bio-Product, San Diego, Calif.); nondisposable devices were sterilized by ultraviolet irradiation between uses. Negative and positive controls (without DNA template and with DNA template, respectively) extracted from the MBM-V sample treated at a low temperature $\left(80^{\circ} \mathrm{C}\right)$ were included in each assay. DNA size markers were phage $\lambda$ digested with EcoRI-HindII (Fig. 2) and a $1 \mathrm{~Kb}$ Plus DNA ladder (Invitrogen, Carlsbad, Calif.).

Bovine-specific mtDNA competitive template and competitive PCR assay. A bovine mtDNA homologous competitive template encompassing the 3 '-terminal portions of the COX2, tRNA ${ }^{\text {Lys }}$, and ATPase 8 genes and the $5^{\prime}$-terminal portion of the ATPase 6 gene was synthesized by a modification of the overlap extension method consisting of a three-step recombinant PCR procedure $(11,13)$. The template contained an insertion of $22 \mathrm{bp}$ located between primers L8249 and H8357 (position 8262). The competitive template was synthesized with primers L8014 (external forward primer; 5'-ACCCATTGTCCTTGA GTTAGT-3'), H8393 (external reverse primer; 5'-GAGGGTTACAAAGCGATTGCT-3'), H8242 (internal reverse primer; 5'-GAGATCTGCCGTACAGGCCTAGAATATTTTTGTTGGTGTCAGT-3'), and L8283 (internal forward primer; 5'-CTAG GCCTGTACGGCAGATCTCA A A A C A A A A C A C C C C T TGAGA-3') by overlap extension. Internal primers L8283 and H8242 carry $3^{\prime}$-terminal tails, which were used to introduce the 22-bp insertion stretches (underlined primer sequences) that allowed discrimination between the bovine and the competitive PCR products. The synthetic competitor was cloned in the pBlueScript $\mathrm{KS}^{+}$vector of Stratagene (La Jolla, Calif.) and purified with the plasmid Maxi-kit DNA isolation system (Qiagen, Hilden,

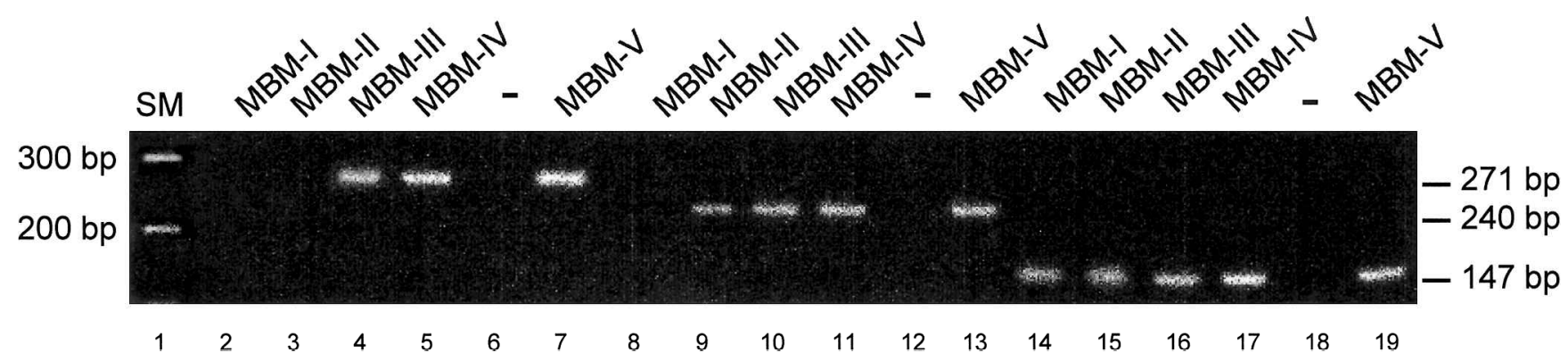

FIGURE 2. Gel electrophoresis of the PCR products of the three bovine mtDNA amplicons. Amplification products from equal volumes of the DNA samples extracted from the same quantity of four MBMs (MBM-I through MBM-IV) were run together with a 1-kb ladder (lane 1) and with negative and positive extraction (MBM-V) controls. Equal volumes of PCR products were loaded on the gel to compare the amplifiability of the 271-bp (lanes 2 through 7), 240-bp (lanes 8 through 13), and 147-bp (lanes 14 through 19) amplicons. 
Germany). To verify the absence of nucleotide misincorporation, the plasmid competitive template was sequenced on both strands with the Sequenase 2.0 DNA sequencing kit (USB, Pharmacia). The concentration of the plasmid competitive template was estimated to be $2.97 \mu \mathrm{g} / \mu \mathrm{l}$ by UV spectrophotometry, and a single serial dilution was prepared and stored at $-80^{\circ} \mathrm{C}$.

To obtain a rough estimate of the endogenous mtDNA content of each MBM sample, competitive amplifications were carried out through titration against a broad range of the plasmid competitive template dilutions in log increments. Thereafter, a second titration, over narrowed dilution ranges, was performed. To obtain a precise determination of the relative mtDNA amount in an MBM sample, endogenous-competitive template mixes, obtained through DNA coextraction of a fixed amount of MBM and serial dilution of the synthetic competitive template, were used for each PCR reaction. With this approach, fluctuations in experimental determinations due to variation in DNA extraction efficiency levels for different MBM samples were minimized (24, 26). PCR conditions were as reported above except that $5 \mu$ l of endogenous-competitive extracted template mix was used. To quantify target and competitive amplified products, $20 \mu \mathrm{l}$ of PCR reaction was loaded on a $3 \%$ agarose gel and the intensity of the ethidium bromide fluorescence was determined. Image acquisition was achieved with the Gel Doc 2000 gel documentation system (Bio-Rad, Hercules, Calif.), and densitometry analysis was carried out with Quantity One software (version 4.0.1, Bio-Rad). PCR products were quantified by capillary electrophoresis with the ABI prism 310 apparatus and GeneScan software (Applied Biosystems). Primers for the automated fragment analysis were 5' conjugated to 6-Fam. Semiquantitative determinations were made by plotting observed target-to-competitive-product band intensity ratios (normalized by molecular weight difference) against the amount of competitive template added to the sample before the extraction. The quantity of bovine mtDNA was estimated by determination of the abscissa value corresponding to the equivalent point (target product/competitive product ratio $=1$ ).

Relative bovine mtDNA amounts were estimated from a semiquantitative PCR analysis carried out on three independent DNA extractions. The statistical significance of differences between data distributions was determined by the two-tailed Student's $t$ test with a significance level of $P<0.05$.

\section{RESULTS}

mtDNA amplification and temperature treatment. Amplification of the 147-bp amplicon was observed for the BACC-3 DNA extracts from the MBM-I sample, which was treated according to the European guidelines (Fig. 2). By contrast, no product was observed with the adoption of primer pairs amplifying the 271- and 240-bp target sequences. The 271-bp amplicon was successfully amplified from MBM-III (dry conditions without overpressure) and MBM-IV $\left(122^{\circ} \mathrm{C}, 200 \mathrm{kPa}, 20 \mathrm{~min}\right)$. The primer combination used to amplify the 240-bp fragment also allowed the identification of bovine mtDNA in DNA extracts obtained from MBM-II $\left(130^{\circ} \mathrm{C}, 270 \mathrm{kPa}, 20 \mathrm{~min}\right)$. However, all amplicons were amplified from MBM-V, which was used as a positive control. Results are summarized in Figure 2.

On the basis of our results, we evaluated the DNA amounts and the degradation levels of the total DNA extracted from the different MBM samples by agarose gel electrophoresis. As shown in Figure 3, total DNA extracted from heat-treated MBM samples exhibited very low mo-

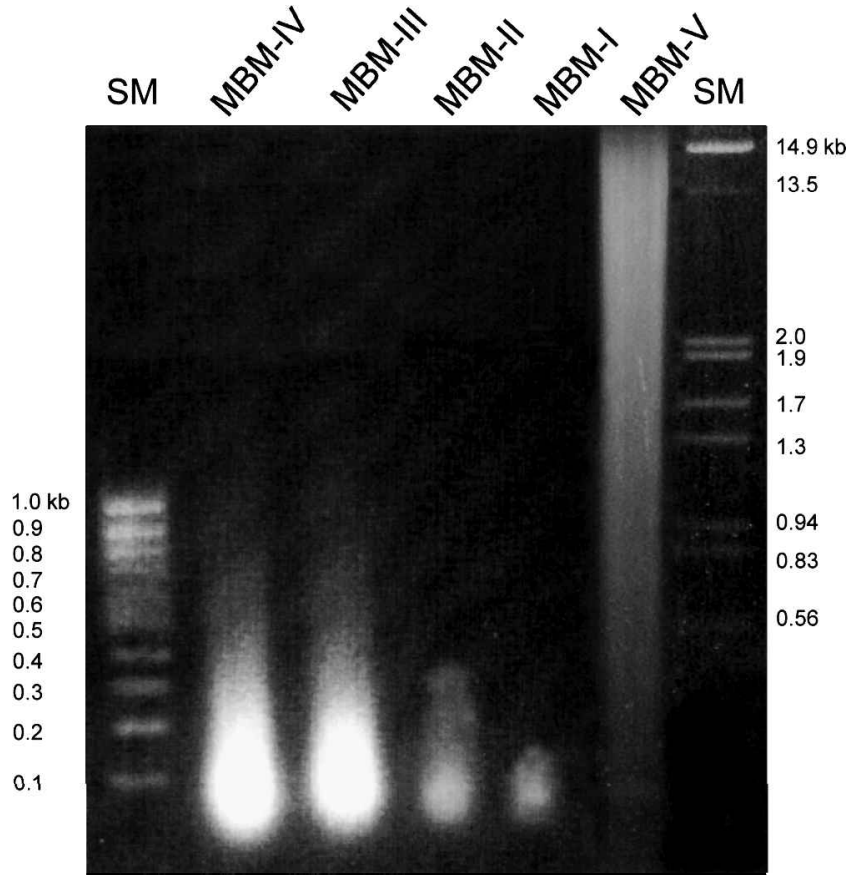

FIGURE 3. Gel electrophoresis of total genomic DNA extracted from the different MBM samples. Five percent of the total DNA extracted from MBM-III, MBM-IV, and MBM-V and $15 \%$ of the total DNA extracted from MBM-I and MBM-II were loaded.

lecular weight compared with the lightly treated MBM-V sample. Moreover, relatively smaller amounts of total DNA were extracted from MBM-III and MBM-IV samples. Significantly, a reduction in the quantity and size of extracted DNA was correlated with an increase in treatment temperature for the four MBM samples.

On the whole, these results indicate a correlation between DNA degradation and MBM heat treatment, and they also demonstrate the efficiency of the 147-bp PCR-based assay in the detection of mtDNA in MBM treated according to the European standard.

Competitive PCR assay for comparison of mtDNA amounts in heat-treated MBM samples. Results from representative amplifications are shown in Figure 4. In all of the competitive PCR assays, a titration effect was observed whereby the competitive product decreased in intensity as the competitive template concentration diminished, whereas the bovine target product increased in intensity because of the gradual decrease in annealing competition during amplification. Equal competition between synthetic and target templates was reached at different competitor concentrations of the different amplicons. The graphic representation of titration indicates that the estimated concentration of the 147-bp amplicon DNA template in MBM-IV is three- and sevenfold higher than those of the 240- and 271bp template sequences, respectively (Fig. 4A).

To determine the effect of heat treatment on DNA degradation, we also evaluated the relative amounts of the 147bp template sequence in MBM-I, MBM-II, and MBM-III samples (Fig. 4B). The experiments were performed with a single serial dilution of the competitive template ranging from $10^{-4}$ to $10^{-6}$ of the starting concentration. As shown 
A

MBM-IV

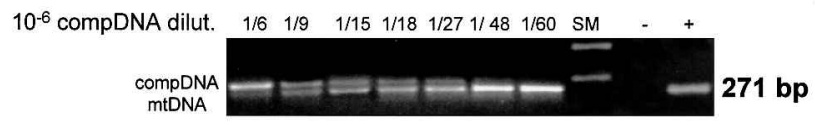

$\begin{array}{llllllllllll}10^{-5} & \text { compDNA dilut. } \quad 1 / 3 & 1 / 6 & 1 / 9 & 1 / 15 & 1 / 18 & 1 / 27 & 1 / 48 & 1 / 60 & \text { SM } & -\end{array}$
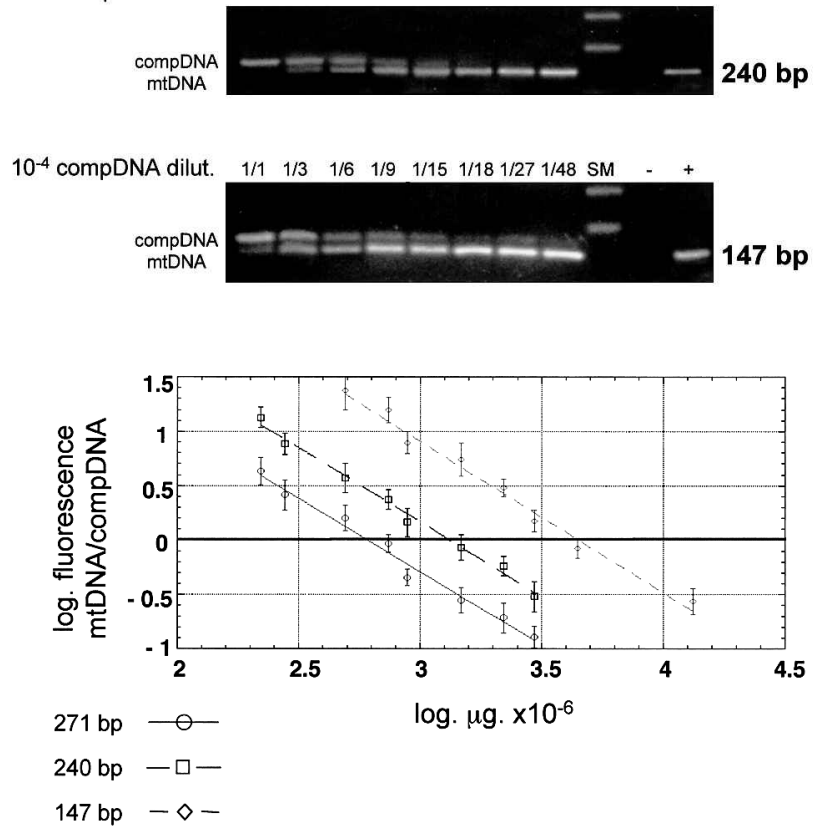

B
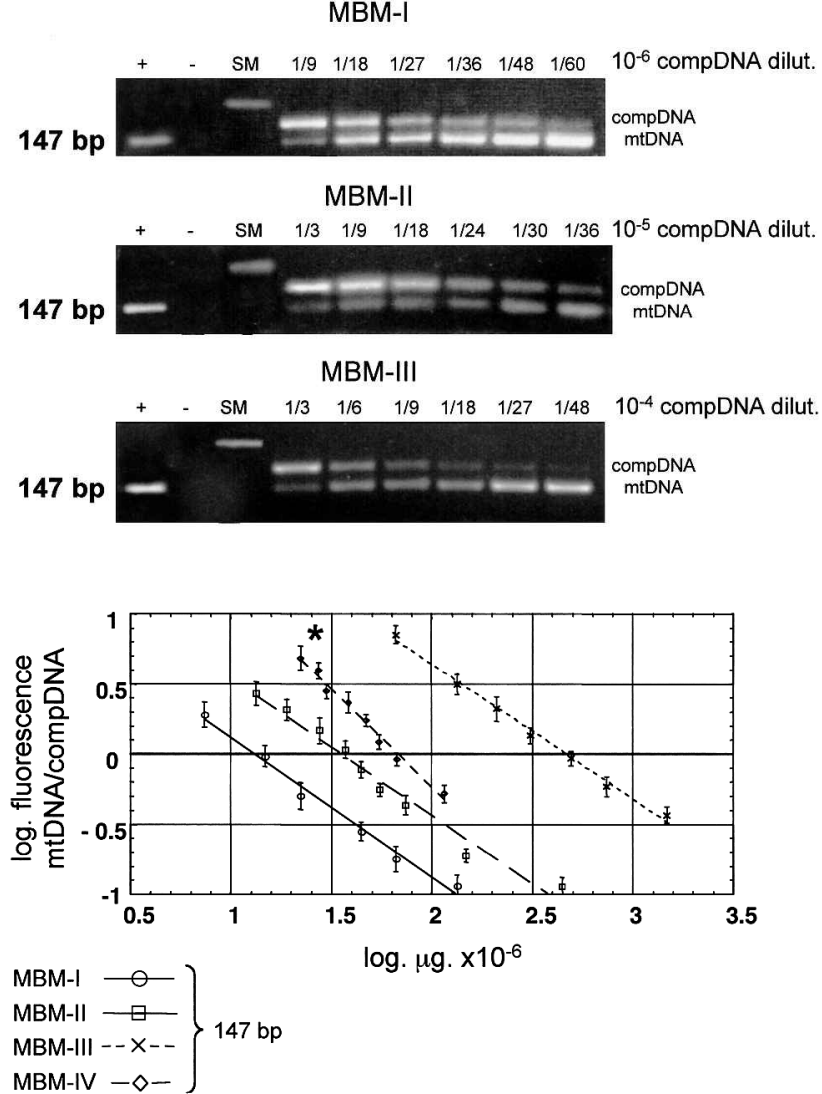

FIGURE 4. Gel electrophoresis of representative competitive PCR assays (each lane is numbered by the fold dilution of a start concentration of the competitor) and diagrams of the semiquantitative determinations based on three independent experiments. Band intensity ratios (fluorescence) of target mtDNA to competitive amplified products (normalized by molecular weight difference and expressed as log values) are plotted as a function of the amount of competitive template added to each sample before extraction. Mean values ( $\pm S E$ ) of 271-, 240-, and 147-bp mtDNA/competitor DNA abundance are reported. mtDNA/competitor DNA isomolarity (log of ratio $=1)$ allows direct comparison of the relative abundances of the DNA targets. (A) Competitive PCR of MBM-IV sample with the 271-, 240-, and 147-bp bovine mtDNA amplicons. (B) Competitive PCR of the MBM-I, MBM-II, and MBM-III samples with the 147bp bovine mtDNA amplicon. The diagram also includes the semiquantitative determination for MBM-IV with the 147-bp amplicon. * Since MBM-IV was made up of $100 \%$ bovine material, its working dilution was half those of MBM-I, MBM-II, and MBM-III, which contained $50 \%$ bovine material.

in Figure 4, equivalence was reached for synthetic and target PCR products at different competitor template concentrations in the MBM samples, supporting an inverse correlation between heat treatment and bovine mtDNA concentration for MBM. The plot of titration experiments indicates that a dramatic decrease in the copy number of mtDNA suitable for 147-bp fragment amplification occurred with heat treatments at $130^{\circ} \mathrm{C}$. The $147-\mathrm{bp}$ amplicon template concentration in MBM-I was estimated to be 3-, 35-, and 5-fold lower than those in MBM-II, MBM-III, and MBM-IV, respectively (Fig. 4B). It should be noted that the competitor concentrations used for the quantitative analysis of MBM-IV-made up of $100 \%$ bovine material-were half those of MBM-I, MBM-II, and MBM-III, which contained only $50 \%$ bovine material. Similar results were obtained when ABI Prism 310 capillary electrophoresis was used to measure synthetic and target PCR products. No statistical difference was observed when the two detection procedures were compared (data not shown).

\section{DISCUSSION}

Recently, we and other research groups have discussed the promising aspects of a molecular approach to the detection of taxon-specific components in animal feeds (16). Nevertheless, up to now the use of such an approach in field conditions has led to some problems with regard to the reliability of the results, as indicated by an intercomparison study involving the testing of $\mathrm{MBM}$ in feed $(1,29)$. To improve the reproducibility and sensitivity of this approach, we have introduced a faster and simpler commercially available method for DNA extraction and optimized the PCR procedure by selecting appropriate target templates. We therefore evaluated the amplification efficiency levels of templates of different lengths (147, 240, and 271 bp) in MBM samples treated under different controlled conditions. We observed the amplification of the 147-bp template for all of the MBM samples, including the one treated according to the severe temperature specified in the EU standard, while the amplification of longer templates was 
observed only for MBM samples treated at lower temperatures. These results indicate that a PCR-based method designed to amplify relatively short mtDNA sequences (147 bp) can be successfully used to analyze MBM and feeds and that the comparison of the amplification efficiency levels of 147-, 240-, and/or 271-bp target templates represents a useful tool for the verification of MBM temperature treatments.

The temperature-dependent DNA degradation was also assessed by a semiquantitative competitive PCR. With this technique, it was possible to compare the quantities of different mtDNA targets in the same MBM sample treated at $122^{\circ} \mathrm{C}$ and to determine the amount of 147-bp mtDNA in the four heat-treated MBM samples. In particular, quantitative determination of the amplifiability of template DNA after heat treatments demonstrated that degradation produces a reduction in DNA length, which leads to a decrease in total DNA. In agreement with these results are the findings of other investigators with regard to the effects of heat treatments on bovine and porcine proteins reported in previous studies carried out with the same test materials used in our study $(2,29)$. These studies revealed that the immunoassay responses of MBM-I and MBM-II were drastically reduced but still distinguishable, with the responses for MBM-II being somewhat higher than those for MBM-I. In contrast, the immunoassay responses for MBM-III were only slightly decreased compared with the control, indicating that the impact of dry-sterilization conditions on this material was less pronounced.

In conclusion, the present results indicate that the competitive PCR-based approach could potentially be used to test for the presence of mtDNA in MBM and feeds and to evaluate the appropriate heat treatment conditions in the legislative framework of BSE prevention. These objectives can be achieved by determining the different quantities of the three templates within a single DNA extract using the same coextracted competitive DNA and standard reference samples of animal feeds containing various MBM concentrations. Furthermore, coextraction of the competitive DNA represents a useful internal control for use in evaluating the efficiency levels of both the extraction and the amplification procedures.

\section{ACKNOWLEDGMENTS}

We thank Ernestina Saulle for skillful technical assistance and Palma Mattioli for the preparation of the figures. We thank Mary Lo Ponte for revising the paper. This work was supported by funds from MURST and Ministero della Sanita'

\section{REFERENCES}

1. Ansfield, M. 1994. Production of a sensitive immunoassay for detection of ruminant proteins in rendered animal material heated to $>130^{\circ}$ C. Food Agric. Immunol. 6:419-433.

2. Björklund, E., L. Pallaroni, W. Unglaub, and C. von Holst. 2001 Method for the determination of appropriate heat treatment of animal meal by immunoassay developed for detection of cooked beef: interlaboratory study. J. AOAC Int. 84:1839-1845.

3. BSE Inquiry. 2000. The BSE Inquiry report, vol. 1. Findings and conclusions, chapter 12. Science and research, paragraph 1122 Available at: www.bse.org.uk/report/volume1/chapt122.htm.

4. BSE Inquiry. 2000. The BSE Inquiry report, vol. 2. Science, chapter
3. The nature and cause of BSE, paragraph 3.123. Available at: www.bse.org.uk/report/volume2/chaptea5.htm.

5. Butler, D. 1996. Did UK 'dump' contaminated feed after ban? Nature 381:544-545.

6. Commission of the European Communities. 1994. Commission decision 94/381/EC of 27 June 1994 concerning certain protection measures with regard to bovine spongiform encephalopathy and the feeding of mammalian derived protein. J. Eur. Communities L 172: 0023-0024

7. Commission of the European Communities. 1998. Commission directive 98/88/EC of 13 November 1998 establishing guidelines for the microscopic identification and estimation of constituents of animal origin for the official control of feedingstuffs. J. Eur. Cотmunities L 318:45-50.

8. Commission of the European Communities. 2000. Commission decision 2000/418/EC of 29 June 2000 regulating the use of material presenting risks as regards transmissible spongiform encephalopathies and amending decision 94/474/EC. J. Eur. Communities L 158: 0076-0082.

9. Commission of the European Communities. 2001. Commission decision 2001/25/EC of 27 December 2000, prohibiting the use of certain animal by-products in animal feed 4143. J. Eur. Communities L 006:16-17.

10. Council of the European Communities. 1999. Council decision 99/ 534/EC of 19 July 1999 on measures applying to the processing of certain animal waste to protect against transmissible spongiform encephalopathies and amending commission decision (97/735/EC). Off. J. Eur. Communities L 204:0037-0042.

11. Dillon, P. J., and C. A. Rosen. 1990. A rapid method for the construction of synthetic genes using the polymerase chain reaction. Biotechniques 9:298-300.

12. Diviacco, S., P. Norio, L. Zentilin, S. Menzo, M. Clementi, G. Biamonti, S. Riva, A. Falaschi, and M. Giacca. 1992. A novel procedure for quantitative polymerase chain reaction by coamplification of competitive templates. Gene 122:313-320.

13. Ho, S. N., H. D. Hunt, R. M. Horton, J. K. Pullen, and L. R. Pease. 1989. Site-directed mutagenesis by overlap extension using the polymerase chain reaction. Gene 77:51-59.

14. Hofmann, K. 1996. Erhitzungsnachweis bei Tiermehlen-sind Tiermehle in Deutschland ausreichend erhitzt? Fleischwirtschaft 76:707711

15. Hofmann, K., K. Fischer, E. Mueller, and V. Kemper. 1995. Versuche zum Nachweis der Erhitzungseffektivitaet bei Fleischkonserven und Tiermehlen. Fleischwirtschaft 75:1227-1231.

16. Lahiff, S., M. Glennon, L. O'Brien, J. Lyng, T. Smith, M. Maher, and N. Shilton. 2001. Species-specific PCR for the identification of ovine, porcine and chicken species in meat and bone meal (MBM). Mol. Cell. Probes 15:27-35.

17. Meyer, R., F. Chardonnens, P. Hubner, and J. Luthy. 1996. Polymerase chain reaction (PCR) in the quality and safety assurance of food: detection of soya in processed meat products. Z. Lebensm. Unters. Forsch. 203:339-344.

18. Michaels, G. S., W. W. Hauswirth, and P. J. Laipis. 1982. Mitochondrial DNA copy number in bovine oocytes and somatic cells. Dev. Biol. 94:246-251.

19. Momcilovic, D., and A. Rasooly. 2000. Detection and analysis of animal materials in food and feed. J. Food Prot. 63:1602-1609.

20. Montiel-Sosa, J. F., E. Ruiz-Pesini, J. Montoya, P. Roncales, M. J. Lopez-Perez, and A. Perez-Martos. 2000. Direct and highly speciesspecific detection of pork meat and fat in meat products by PCR amplification of mitochondrial DNA. J. Agric. Food Chem. 48: 2829-2832.

21. Moya, L. A., J. E. Garrido, J. Guerrero, G. Lizaso, and A. Gomez. 1995. Quality control of raw materials in the feed compound industry, p. 111-116. In G. D. Batten (ed.), Leaping ahead with near infrared technology. Royal Australia Chemical Institute, Melbourne University Press, Melbourne, Australia.

22. Myers, M. J., S. L. Friedman, D. E. Farrell, D. A. Dove-Pettit, M. F. Bucker, S. Kelly, S. Madzo, W. Campbell, R. F. Wang, D. Paine, and C. E. Cerniglia. 2001. Validation of a polymerase chain reaction 
method for the detection of rendered bovine-derived materials in feedstuffs. J. Food Prot. 64:564-566.

23. Robin, E. D., and R. Wong. 1988. Mitochondrial DNA molecules and virtual number of mitochondria per cell in mammalian cells. $J$. Cell Physiol. 136:507-513.

24. Rodrigo, A. G., P. C. Goracke, K. Rowhanian, and J. I. Mullins. 1997. Quantitation of target molecules from polymerase chain reaction-based limiting dilution assays. AIDS Res. Hum. Retroviruses 13:737-742.

25. Saulle, E., S. Di Pasquale, and M. Tartaglia. 1999. Rapid communication: nucleotide sequence of chamois, alpine ibex, and red deer tRNA(Lys) and ATPase8 mitochondrial genes. J. Anim. Sci. 77 3398-3399.

26. Tartaglia, M., A. Fragale, and P. A. Battaglia. 2001. A competitive PCR-based method to measure human fibroblast growth factor receptor 1-4 (fgfr1-4) gene expression. DNA Cell Biol. 20:367-379.
27. Tartaglia, M., and E. Saulle. 1998. Rapid communication: nucleotide sequence of porcine and ovine tRNA(Lys) and ATPase8 mitochondrial genes. J. Anim. Sci. 76:2207-2208.

28. Tartaglia, M., E. Saulle, S. Pestalozza, L. Morelli, G. Antonucci, and P. A. Battaglia. 1998. Detection of bovine mitochondrial DNA in ruminant feeds: a molecular approach to test for the presence of bovine-derived materials. J. Food Prot. 61:513-518.

29. von-Holst, C., W. Unglaub, K. O. Honikel, G. Kramer, and E. Anklam. 2000. Determination of an appropriate heat treatment of animal waste by using the ELISA technique: results of a validation study. Meat Sci. 54:1-7.

30. Wolf, C., and J. Lüthy. 2001. Quantitative competitive (QC) PCR for quantification of porcine DNA. Meat Sci. 57:161-168.

31. Zimmermann, K., and J. W. Mannhalter. 1996. Technical aspects of quantitative competitive PCR. Biotechniques 21:268-279. 